
\section{С.В. Лук'янюк, науковий співробітник С.Ю. Чайковський, с.н.с.}

Український науково-дослідний інститут спеціальної техніки та судових експертиз Служби безпеки України, м. Київ

\title{
Перспективні рішення щодо автоматизації методів вимірювання в нанометричному діапазоні
}

(Представлення: к.т.н., ст. викладач Блячина М.В.)

\begin{abstract}
У статті наголошено, щзо нанометрологія є невід’ємною складовою нановиробництва, а світовий ринок наноматеріалів активно розвивається $і$ його ємність у 2019 р. оцінювалася в 8,5 млрд дол. США з перспективою зростання на 13,1 \% на період до 2027 р. При иььому створюються нові перспективні нанотехнології $і$ наноматеріали. А ие вимагає розвитку системи нанометрології. Вважається, щуо система нановиробництво - нанотехнологія має розв 'язувати такі задачі: автоматичне інтелектуальне вимірювання з допомогою числового програмного управління (ЧПУ) з вбудованою міні-ЕОМ; автономне або онлайн програмування вимірювальних інструментів ЧПУ з вбудованою міні-EОМ; автоматизована заміна заготовок $i$ виробів; автоматизована заміна зондів $і$ датчиків; автоматизована оцінка результатів вимірювань. У світі створена та використовується велика гама електронних мікроскопів для оцінки геометрії нановиробів. Проте розвиток нанотехнологій вимагає оснащення їх автоматизованими системами та відповідним програмним забезпеченням. Створено експериментальний автоматизований прилад (інтерференційний профілометр) та програмне забезпечення для безконтактного вимірювання мікро- та нанотопографії поверхні виробу, ї̈ тривимірного представлення, визначення показників шорсткості та параметрів сканування. Розроблено автоматизовану систему вимірювання і контролю для атомно-силової мікроскопії (АСМ), яка має удосконалений блок контролю систем позиціонування лазерного променя на зонд АСМ. Одним із напрямів автоматизації лінійних вимірювань у нанометрологї $є$ використання еталонів порівняння, а для изього необхідне відповідне корегування державних стандартів нанометрології. Проведений аналіз опублікованих матеріалів свідчить про певні позитивні результати у справі автоматизачії нановимірювань у середовищі нановиробництва. Проте очевидно, що цей напрям діяльності потребує збільшення фінансування та нових ідей для забезпечення конкурентоздатності нановиробів.
\end{abstract}

Ключові слова: наноматеріали; нанометрологія; вимірювання розмірів; автоматизація; програмне забезпечення.

Актуальність теми. Вироби та порошки з розмірами нанометрового діапазону знаходять все більше застосування в багатьох галузях: від металургії та біології до фармацевтики й косметики. Суттєво на експлуатаційні характеристики товарів 3 нанодобавками впливають їх геометричні розміри та кількість. Тому вимірювання розмірів наноматеріалів і нановиробів $\epsilon$ актуальною проблемою. Виробництво нових продуктів на базі нанотехнологій здебільшого залежить від здатності точно вимірювати їх параметри в нанометровій шкалі та відтворювати серійно їх властивості. Для цього розроблено та використовується в основному електронна мікроскопія. Проте вона має певні обмеження стосовно точності та можливостей у розрізі сучасних у майбутніх нанотехнологій. В той же час дослідження складних наносистем вимагає отримання їх 3D зображення та автоматизації процесу. Все це дозволить підвищити якість наукових досліджень, точність виробничої метрології та екологічну безпеку. Стандартизовані прилади та метрологія $\epsilon$ важливими для забезпечення контролю якості нанопродукції. Розроблені та прийняті стандарти вимірювання наносистем будуть необхідні для забезпечення конкурентної здатності України на глобальному ринку.

Аналіз останніх досліджень та публікацій. Проблемам нанометрії присвятили свої публікації: В.П. Квасніков [2], J.M. Bauer [4], N.M. Durakbasa [6], S.C. Glotzer [7], B.I. Закієв [10], М.О. Бондаренко [11], П.А. Тодуа [12], С.Б. Ковшов [13] та ін.

Метою статті $\epsilon$ аналіз та узагальнення інформації стосовно сучасних напрямів автоматизації вимірювання в нанометрології.

Викладення основного матеріалу. Світовий ринок наноматеріалів розвивається досить динамічно i в 2019 р. його обсяг оцінювався у 8,5 млрд дол. США. Очікується, що з 2020 до 2027 р. він зростатиме за 
річним темпом (CAGR) 13,1 \% і досягне обсягу 22,9 млрд дол. США [1]. Стимулюватимуть вказаний ринок медичний сегмент, а саме розвиток фармацевтики, нанодіагностики та нанороботів, частка якого в 2019 р. становила 29,1 \% світового ринку. Друге місце на світовому ринку наноматеріалів займає сегмент електронної промисловості. Його розвитку сприяє попит на високотехнологічну продукцію на базі інтегральних схем. Крім того, наноматеріали використовують в енергетиці (акумулятори, паливні елементи, сонячні панелі), автомобілебудуванні (автомобільні фарби та покриття) та нанобіоінженерії. В свою чергу розвиток ринку наноматеріалів і нанотехнологій стимулює розвиток нанометрології та використання широкої гами електронних засобів вимірювання геометричних характеристик нановиробів у діапазоні від 100 до 0,1 нм [2-4]. Серед них скануюча тунельна мікроскопія (scanning tunneling microscopy, STM); контактна скануюча атомно-силова мікроскопія (Касма); переривчасто-контактна скануюча силова мікроскопія; безконтактна атомно-силова мікроскопія (Non Contact AFM); растрова електронна мікроскопія (РЕМ); просвітчаста електронна мікроскопія (ПЕМ); атомно-силова мікроскопія (atomic force microscopy, AFM); мікроскопія на основі сфокусованих іонних пучків; вторинна іонна масспектрометрія; оже-спектроскопія, а також оптична мікроскопія (near-field scanning optical microscopy, NSOM) тощо. Bauer J.M. [4], а також Bas G., Durakbasa N.M. i Kopacek P. [6] зауважують, що 3Dвимірювання поверхонь виробів $є$ важливим інструментом при аналізі таких характеристик поверхні, як зношуваність, топографія, проблеми контакту та функціональна поведінка поверхонь. Такі дослідження виконуються в лабораторії нанометрології Віденського технологічного університету за допомогою атомно-силового мікроскопа. Метод вимірювання базується на скануванні профілю поверхні, в якому висоти рельєфу визначаються за допомогою механічного притягання або сили відштовхування між наконечником зонда та поверхнею згідно ISO 25178-6: 2010 Geometrical product specifications (GPS) Surface texture: Areal - Part 6: Classification of methods for measuring surface texture. У роботі Guo P. [5] показано, що під час дослідження біологічних нанооб'єктів використовується найсучасніший метод флуоресцентного резонансного переносу енергії (Fluorescence Resonance Energy Transfer, FRET). Це одномолекулярний метод, за допомогою якого відстань між двома молекулами можна визначити, коли вони знаходяться в безпосередній близькості (у межах 10 нм). Одна молекула (донор) збуджується лазером. Одночасно близька для донора друга молекула (акцептор) збуджується до флуоресценції. Величина переданої енергії, яка вимірюється спеціальним приладом, пропорційна відстані між донором і акцептором. Розроблено формулу для розрахунку відстані між молекулами. Цей метод можна використовувати для вимірювання відстані як між-, так і внутрішньомолекулярно.

В той же час процеси виробництва нановиробів і проведення їх нановимірювань слід розглядати як єдину систему, яка має бути комплексно оптимізованою та автоматизованою. Ряд науковців, таких як: J.M. Bauer [4], а також G.Bas, N.M. Durakbasa, P.Kopacek, L.Kräuter [6] вважають, що така система має розв'язувати такі задачі:

- автоматичне інтелектуальне вимірювання з допомогою числового програмного управління (ЧПУ) з вбудованою міні-ЕОМ;

- автономне або онлайн програмування вимірювальних інструментів ЧПУ з вбудованою міні-ЕОМ;

- автоматизована заміна заготовок і виробів;

- автоматизована заміна зондів і датчиків;

- автоматизована оцінка результатів вимірювань.

Така інтегрована система нановиробництво - нанометрологія має забезпечувати високу якість продукції, iі помірну вартість та конкурентоздатність на ринку, а також розширювати експортні можливості виробника.

Наразі розвиток нанометрології вимагає розробки надійних моделей для інтерпретування результатів вимірювання, створення нових нанометричних інструментів і методологій, надання користувачам віртуальних засобів вимірювання нанорозмірних властивостей об'єктів і забезпечення швидкого доступу до реального та віртуального нановимірювання. В найближчій перспективі очікуються проривні рішення в інформаційних технологіях, математиці та статистиці стосовно нанометрології [7].

Має сенс зазначити, що згідно з рекомендаціями Європейської комісії до класу наноматеріалів належать матеріали, які містять 50 \% і більше частинок розмірами від 1 до 100 нм [8].

Виходячи $з$ наведеного, актуальною є розробка автоматизованих методів сортування наночасточок за ïx розміром. Це дозволить усувати негативний вплив часточок певного розміру на механічні, оптичні чи екологічні властивості наносистем. Такі технології мають бути експресними, надійними та придатними до використання в умовах виробництва, враховуючи їх безпечність для здоров’я персоналу [9].

Проте очевидно, що на першому плані мають знаходитися нові ідеї щодо автоматизації нановимірювань нановиробів.

Закієвим В.I. розроблено експериментальний автоматизований прилад (інтерференційний профілометр) та програмне забезпечення для безконтактного вимірювання мікро- та нанотопографії поверхні виробу, ії тривимірного представлення, визначення показників шорсткості та параметрів сканування [10]. Автоматизація роботи приладу забезпечується двома програмами. Перша програма для 
управління режимами роботи електронних компонентів (команди на перетворення, управління, формування, усереднення та передачу даних) прошивається у мікропроцесор електронного блоку. Друга програма використовується для управління, налаштування, збору, обробки та збереження даних, а також для фільтрації та тривимірної візуалізації отриманих результатів й інсталюється на робочий комп'ютер. Також розроблено методику та програмне забезпечення для автоматичного юстирування приладу. Перевагами цього приладу є безконтактність, висока роздільна здатність (близько 1 нм), великий діапазон вимірювання висот мікронерівностей та площі сканування, а також швидкість вимірювання (менше 1 хвилини). Зауважимо, що в Україні автоматизовані інтерференційні профілометри не виробляються.

Перспективним при розробці технологій виробництва компонентів мікросистемної техніки (MCT) $є$ використання атомно-силової мікроскопії [11]. Остання порівняно з іншими методами має вищу атомарну роздільну здатність при визначенні параметрів рельєфу поверхонь композиційних матеріалів, високу чутливість зонду та гнучкість режимів роботи. Крім того, метод АСМ дозволяє проводити дослідження на повітрі, у вакуумі і в рідкому середовищі. Виходячи з наведеного, було розроблено автоматизовану систему вимірювання і контролю для АСМ. Вона містить удосконалений блок контролю систем позиціонування лазерного променя на зонд АСМ (патент України на корисну модель № 91523) та спеціалізоване програмне забезпечення. Це дозволило підвищити точність результатів контролю характеристик компонентів МСТ: зменшити відносну похибку на $10-15$ \% та час контролю у 1,2-1,3 раза, а також збільшити термін безвідмовної роботи зонду на 5-11\%.

Одним із напрямів автоматизації лінійних вимірювань у нанометрології $\epsilon$ використання еталонів порівнювання [12]. Їх застосування дозволяє створювати автоматизовані вимірювальні комплекси на базі растрових електронних мікроскопів. Так в науково-дослідному центрі з вивчення властивостей поверхні та вакууму (научно-исследовательский центр по изучению свойств поверхности и вакуума, Москва) створені автоматизовані комплекси для лінійних вимірювань у діапазоні від 1 до 100 мкм на базі растрового електронного мікроскопу JSM-6460 LV (фірма «JEOL», Японія) та растрового електронного мікроскопа надвисокої роздільної здатності S-4800 (фірма «Hitachi», Японія). Для забезпечення нормативно-методичної бази нанометрології в РФ розроблені та введені в дію впродовж 2007-2010 рр. 11 національних стандартів блоку «Государственная система обеспечения единства измерений».

У цьому ж напрямі сформовані С.Б. Ковшовим і В.С. Купко [13] рекомендації стосовно модернізації положень ДСТУ 3741-98 «Метрологія. Державна повірочна схема для засобів вимірювань довжини». Вочевидь оновлена версія стандарту (ДСТУ 3741:2015) враховує ці пропозиції.

Доцільність створення інтернет-лабораторії скануючої зондової мікроскопії обгрунтовано та

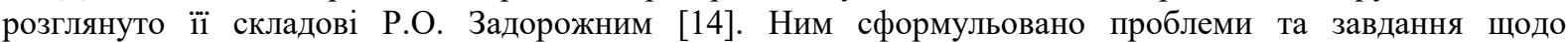
впровадження калібрування скануючих зондових мікроскопів через мережу Інтернет. Запропоновано також метрологічне забезпечення лабораторії скануючої зондової мікроскопії 3 повним доступом до експериментальної установки через мережу Інтернет.

До недоліків визначення характеристик наноматеріалів за допомогою електронної мікроскопії (EM) належать: витрати часу та економічна неефективність. Для їх мінімізації був розроблений метод автоматичного аналізу зображень електронних мікрофотографій твердих частинок за назвою «ParticleSizer» [15]. Цей метод пропонує високий рівень автоматизації для вимірювання розподілу характеристичних властивостей, враховуючи мінімальний зовнішній розмір частинок в агрегатах та агломератах, або представлених у вигляді окремих частинок на зображеннях ЕМ. Метод розроблено в межах реалізації рекомендації ЄС щодо визначення наноматеріалу. Він забезпечує інформацію стосовно середніх значень розподілу кількості частинок. Verleysen Е. та іншими [15] вказується, що лабораторії електронної мікроскопії можуть використовувати цей метод, оскільки програмне забезпечення ImageJ для аналізу зображень $є$ безкоштовним. У той же час для отримання точних результатів необхідна підготовка недосвідчених користувачів. Оскільки метод значною мірою автоматизований, то це може зробити оцінку результатів аналізу електронної мікроскопії економічно ефективною і більш точною.

Висновки та перспективи подальших досліджень. Нанометрологія є невід'ємною складовою нановиробництва і забезпечує якість нановиробів та їх конкурентоздатність на ринку. В світі розроблена та використовується велика гама приладів, які проводять вимірювання в нанодіапазоні. Проте все нові технологічні рішення в нановиробництві вимагають впровадження сучасних методів автоматизації нановимірювань та розробки відповідного програмного забезпечення. Ключовими напрямами автоматизації в найближчій перспективі у системі нановиробництво - нанометрологія $\epsilon$ забезпечення автоматичного вимірювання 3 використанням програмного забезпечення, автономне програмування вимірювальних інструментів, автоматизована заміна об'єктів вимірювання та зондів і датчиків, а також автоматизована оцінка результатів вимірювань.

\section{Список використаної літератури:}

1. Nanomaterials Market Size, Share \& Trends Analysis Report By Product (Carbon Nanotubes, Titanium Dioxide), By Application (Medical, Electronics, Paints \& Coatings), By Region, And Segment Forecasts, 2020-2027. - May, 
2020. - 113 p. [Electronic resource]. - Access mode: https://www.grandviewresearch.com/industryanalysis/nanotechnology-and-nanomaterials-market.

2. Квасніков В.П. Аналіз і класифікація метрологічного забезпечення вимірювань рельєфу нанооб'єктів / В.П. Квасніков, М.О. Катаєва // Вісник Черкаського державного технологічного університету. - 2021. № $1 .-$ C. $50-58$.

3. Instrumentation and Metrology for Nanotechnology : Report of the National Nanotechnology Initiative Workshop.Gaithersburg, MD, January 27-29, 2004, - 188 p.

4. Development Trends in Automation and Metrology / J.M. Bauer, G.Bas, N.M. Durakbasa, P.Kopacek // International Federation of Automatic Control IFAC- Hosting by Elsevier Ltd. - 2015. - P. 168-172.

5. Guo P. Determination of Size, Distance and Stoichiometry using Nanoscale Measurement Techniques. Instrumentation and Metrology for Nanotechnology : Report of the National Nanotechnology Initiative Workshop / P.Guo. - January 27-29, 2004. - 137 p.

6. Development of an Advanced Metrology and Intelligent Quality Management as a Strategic Approach in Manufacturing Industry / N.M. Durakbasa, G.Bas, J.M. Bauer, L.Kräuter // 11th International Symposium on Measurement and Quality Control 2013 (September 11-13, Cracow-Kielce). - Poland, 2013. - 4 p.

7. Glotzer S.C. Computational Science in Nanometrology. Instrumentation and Metrology for Nanotechnology : Report of the National Nanotechnology Initiative Workshop / S.C. Glotzer. - January 27-29, 2004. - P. 134-135.

8. Commission Recommendation of XXX on the definition of nanomaterial (Text with EEA relevance). - Brussels : XXX, 2011. $-6 \mathrm{p}$.

9. Future Needs for Nanometrology and Grand Challenges for Responsible Commercialization of Nanotechnology. Instrumentation and Metrology for Nanotechnology : Report of the National Nanotechnology Initiative Workshop / G.S. Blackman, K.C. Doraiswamy, S.C. Freilich et al. - January 27-29, 2004. - P. 132-133.

10. Закієв B.I. Прилад безконтактного вимірювання геометричних параметрів поверхні виробів методом інтерферометрії : дис. ... канд. тех. наук / B.I. Закієв ; Національний авіаційний університет МОН України. Київ, 2019. - 191 с.

11. Бондаренко М.О. Розвиток методів та засобів атомно-силової мікроскопії для неруйнівного контролю характеристик компонентів мікросистемної техніки : автореф. дис. ... д-ра техн. наук / М.О. Бондаренко. Київ, 2019. - 44 с.

12. Тодуа П.А. Нанометрология - ключевое звено инфраструктуры нанотехнологий / П.А. Тодуа // Труды МФТИ. - 2011. - Т. 3. - № 4. - С. 81-96.

13. Ковшов С.Б. Расширение государственной поверочной схемы для средств измерения длины в нанометровом диапазоне / С.Б. Ковшов, В.С. Купко // Метрологія - 2014. - С. 356-359 [Електронний ресурс]. - Режим доступу : http://www.metrology.kharkov.ua/fileadmin/user_upload/data_gc/conference/M2014/pages/07/2.pdf.

14. Задорожній Р.О. Методи та моделі підвищення точності вимірювання геометричних розмірів об'єктів зондовими мікроскопами : автореф. дис. ... канд. техн. наук / Р.О. Задорожній ; Національний науковий центр «Інститут метрології». - Харків, 2010. - 20 с.

15. Evaluation of a TEM based Approach for Size Measurement of Particulate (Nano)materials / E.Verleysen, T.Wagner, H.G. Lipinski et al. // Materials (Basel). - 2019. - Vol. 12. - Issue 14. - 20 p. [Electronic resource]. - Access mode : https://www.ncbi.nlm.nih.gov/pmc/articles/PMC6679035/.

\section{References:}

1. «Nanomaterials Market Size, Share \& Trends Analysis Report By Product (Carbon Nanotubes, Titanium Dioxide), By Application (Medical, Electronics, Paints \& Coatings), By Region, And Segment Forecasts, 2020-2027» (2020), 113 p., [Online], available at: https://www.grandviewresearch.com/industry-analysis/nanotechnology-andnanomaterials-market

2. Kvasnikov, V.P. and Katajeva, M.O. (2021), «Analiz i klasyfikacija metrologichnogo zabezpechennja vymirjuvan' rel'jefu nanoob'jektiv», Visnyk Cherkas'kogo derzhavnogo tehnologichnogo universytetu, No. 1, pp. 50-58.

3. Instrumentation and Metrology for Nanotechnology (2004), Report of the National Nanotechnology Initiative Workshop, Gaithersburg, MD, 188 p.

4. Bauer, J.M., Bas, G., Durakbasa, N.M. and Kopacek P. (2015), Development Trends in Automation and Metrology. International Federation of Automatic Control, IFAC- Hosting by Elsevier Ltd, pp. 168-172.

5. Guo, P. (2004), «Determination of Size, Distance and Stoichiometry using Nanoscale Measurement Techniques», Instrumentation and Metrology for Nanotechnology, Report of the National Nanotechnology Initiative Workshop, $137 \mathrm{p}$.

6. Durakbasa, N.M., Bas, G., Bauer, J.M. and Kräuter, L. (2013), «Development of an Advanced Metrology and Intelligent Quality Management as a Strategic Approach in Manufacturing Industry», 11th International Symposium on Measurement and Quality Control 2013, September 11-13, Cracow-Kielce, Poland, 4 p.

7. Glotzer, S.C. (2004), «Computational Science in Nanometrology», Instrumentation and Metrology for Nanotechnology, Report of the National Nanotechnology Initiative Workshop, January 27-29, pp. 134-135.

8. Commission Recommendation of XXX on the definition of nanomaterial (Text with EEA relevance) (2011), Brussels, XXX, 6 p.

9. Blackman, G.S., Doraiswamy, K.C. and Freilich, S.C. et al. (2004), «Future Needs for Nanometrology and Grand Challenges for Responsible Commercialization of Nanotechnology», Instrumentation and Metrology for Nanotechnology, Report of the National Nanotechnology Initiative Workshop, January 27-29, pp. 132-133.

10. Zakijev, V.I. (2019), «Prylad bezkontaktnogo vymirjuvannja geometrychnyh parametriv poverhni vyrobiv metodom interferometrii'», Ph.D. Thesis of dissertation, Nacional'nyj aviacijnyj universytet MON Ukrai'ny, Kyi'v, 191 p. 
11. Bondarenko, M.O. (2019), «Rozvytok metodiv ta zasobiv atomno-sylovoi' mikroskopii' dlja nerujnivnogo kontrolju harakterystyk komponentiv mikrosystemnoi' tehniky», Abstract of D.Sc. dissertation, Kyi'v, 44 p.

12. Todua, P.A. (2011), «Nanometrologija - kljuchevoe zveno infrastruktury nanotehnologij», Trudy MFTI, Vol. 3. No. 4, pp. 81-96.

13. Kovshov, S.B. and Kupko, V.S. (2014), «Rasshirenie gosudarstvennoj poverochnoj shemy dlja sredstv izmerenija dliny v nanometrovom diapazone», Metrologija - 2014, pp. 356-359, [Online], available at: http://www.metrology.kharkov.ua/fileadmin/user_upload/data_gc/conference/M2014/pages/07/2.pdf

14. Zadorozhnij, R.O. (2010), «Metody ta modeli pidvyshhennja tochnosti vymirjuvannja geometrychnyh rozmiriv ob'jektiv zondovymy mikroskopamy», Abstract of Ph.D. dissertation, Nacional'nyj naukovyj centr «Instytut metrologii'», Harkiv, $20 \mathrm{p}$.

15. Verleysen, E., Wagner, T. and Lipinski, H.G. (2019), «Evaluation of a TEM based Approach for Size Measurement of Particulate (Nano)materials», Materials (Basel), Vol. 12, Issue 14, 20 p., [Online], available at: https://www.ncbi.nlm.nih.gov/pmc/articles/PMC6679035/

Павленко В'ячеслав Якович - старший науковий співробітник Українського науково-дослідного інституту спеціальної техніки та судових експертиз Служби безпеки України, м. Київ.

https://orcid.org/0000-0003-0925-4173.

Наукові інтереси:

- сертифікація продукції;

- сертифікація виробництва;

- вимоги до персоналу, виробничих процесів.

Шорнікова Світлана Василівна - начальник відділу Українського науково-дослідного інституту спеціальної техніки та судових експертиз Служби безпеки України, м. Київ.

https://orcid.org/0000-0002-9038-2457.

Наукові інтереси:

- перспективні рішення щодо вдосконалення алгоритмів зчитування малих відстаней між об'єктами;

- автоматизація систем вимірювання.

Лук'янюк Світлана Василівна - науковий співробітник Українського науково-дослідного інституту спеціальної техніки та судових експертиз Служби безпеки України, м. Київ.

https://orcid.org/0000-0002-7469-8144.

Наукові інтереси:

- автоматизація систем вимірювання.

Чайковський Сергій Юрійович - старший науковий співробітник випробувальної лабораторії Українського науково-дослідного інституту спеціальної техніки та судових експертиз Служби безпеки України, м. Київ.

https://orcid.org/0000-0002-2891-0845.

Наукові інтереси:

- iнноваційні впровадження алгоритмів проведення випробувань технічних засобів в акредитованих лабораторіях при застосуванні механічного та кліматичного обладнання.

Стаття надійшла до редакції 21.10.2021. 